\title{
Neuronal transmission of timing precision: dependence on intrinsic and synaptic properties
}

\author{
Heather A Brooks ${ }^{*}$, Alla Borisyuk \\ From Twenty First Annual Computational Neuroscience Meeting: CNS*2012 \\ Decatur, GA, USA. 21-26 July 2012
}

Precision of spike timing and its role in information processing is one of the key themes in systems neuroscience. As signals travel through nervous systems, the precision and reliability of the timing information is altered. Interestingly, depending on the particular system, the timing precision can be improved or reduced through propagation. For example, at the transmission from auditory nerve to brainstem the emergence of latency precision and jitter reduction is observed [1]. On the other hand, phase locking to stimulus deteriorates across levels of auditory system from very good phase locking at early stages of processing in the brainstem to weaker phase locking in the midbrain (inferior colliculus) to an even weaker one in the auditory cortex [2]. This raises the issue of which properties allow for the improvement or deterioration of the timing information.

Motivated by the processing of timing information in the auditory system, we examine the cellular and synaptic properties that affect improving or decreasing the precision of spike timing through synaptic transmission.

We show through combination of analysis and numerics in minimal neuronal models (integrate-and-fire and Morris-Lecar) that both improvement and deterioration of spike-time precision through transmission is possible, depending on the input times distribution, number of inputs and synaptic strength.

Further, in a conductance-based model we include more nuanced intrinsic and synaptic properties, in particular, currents that switch the neuron from integrator to coincidence detector (Prescott et al., 2006; Svirskis et al., 2004). We characterize response properties that deviate from the performance of an "ideal" integrator

\footnotetext{
* Correspondence: h.brooks11@gmail.com

Department of Mathematics, University of Utah, Salt Lake City, UT 84112,
} USA

(c) 2012 Brooks and Borisyuk; licensee BioMed Central Ltd. This is an Open Access article distributed under the terms of the Creative and coincidence detector in a manner dependent on details of the intrinsic ionic currents.

\section{Acknowledgements}

This work was partially supported by National Science Foundation grants NSF-DMS-1022945, NSF-0602219 and University of Utah Undergraduate Research Opportunity program.

Published: 16 July 2012

\section{References}

1. Covey $\mathrm{E}$, Casseday $\mathrm{JH}$ : The monaural nuclei of the lateral lemniscus of an echolocating bat: Parallel pathways for analyzing temporal features of sound. J. Neurosci 1991, 11:34563470.

2. Joris PX, Smith PH, Yin TC: Coincidence detection in the auditory system: 50 years after Jeffress. Neuron 1998, 21:1234-1238.

3. Prescott SA, Ratte S, De Konick Y, Sejnowski TJ: Nonlinear interaction between shunting and adaptation controls a switch between integration and coincidence detection in pyramidal neurons. J Neurosci 2006, 26(36):9084-909.

4. Svirskis G, Kotak V, Sanes D, Rinzel J: Sodium along with low threshold potassium currents enhance coincidence detection of subthreshold noisy signals in MSO neurons. J Neurophys 2004, 91:2465-2473.

doi:10.1186/1471-2202-13-S1-P177

Cite this article as: Brooks and Borisyuk: Neuronal transmission of timing precision: dependence on intrinsic and synaptic properties. $B M C$ Neuroscience 2012 13(Suppl 1):P177.

Submit your next manuscript to BioMed Central and take full advantage of:

- Convenient online submission

- Thorough peer review

- No space constraints or color figure charges

- Immediate publication on acceptance

- Inclusion in PubMed, CAS, Scopus and Google Scholar

- Research which is freely available for redistribution \\ () Biomed Central}

